\title{
Evaluasi Cold Chain Management Vaksin di Puskesmas Kabupaten Jember
}

\author{
Abdul Syakur ${ }^{*}$, Christyana Sandra*, Candra Bumi* \\ *Fakultas Kesehatan Masyarakat, Universitas Jember \\ Email:abdulsyakur53@gmail.com
}

\begin{abstract}
Immunization is the most cost-effective health prevention method to suppress the incidence of vaccine-preventable disease. Immunization Program in Jember district is still not optimal with many vaccinepreventable disease cases found. Another problem found in Jember is the management of logistics vaccine that is still not optimal. Based on the activity plan report of ORI Difteri 2018, it is known that the logistics needs of some vaccines do not comply with the allocation received by Jember regency of the province. This condition
\end{abstract}

This was a descriptive study using questionaire and observations data as well as the documentation study of the annual Report of Health Pharmacy Installation (IFK) year 2019. Respondent to this study were immunization officers at primary health care of Jember District.

The result of cold chain management evaluation is known that the most are good enaugh. In some primary health care are still hampered insufficient means so that the maintenance of vaccine is still not optimal

Based on the result that cold chain management evaluation, the knowledge officer on cold chain management is still lacking good. In the some primary health care, it is known that the equipment canstraints are unavailable. While in the conformity of temperature only one primary helath care is not recommended. And stirage activities are mostly in accordance with SOP.
Keyword: Immunization, Vaccine, Cold Chain Manajemen, Health Primary Care of Jember District

\section{PENDAHULUAN}

Program imunisasi merupakan metode preventif kesehatan paling cost-effective untuk menekan kejadian kasus penyakit yang dapat dicegah dengan imunisasi (PD3I) antara lain tuberkulosis (TBC), difteri, tetanus, hepatitis $\mathrm{B}$, pertusis, campak, rubella, polio, radang selaput otak, dan radang paru-paru. ${ }^{1}$ Program imunisasi dilaksanakan dengan memberikan kekebalan terhadap individu yang diharapkan memberikan kontribusi tinggi pada kekebalan komunitas (herd immunity). Kekebalan yang terbentuk pada komunitas diharapkan pula mampu menghambat dan memutus rantai penyebaran kasus penyakit di masyarakat. ${ }^{2}$

Penyelenggaraan imunisasi di Indonesia masih belum mampu menekan penyebaran kasus PD3I secara optimal seperti yang tercantum pada profil kesehatan Republik Indonesia 2018 masih ditemukannya berbagai kasus PD3I seperti kasus TBC 566.623 kasus, difteri 1.386 kasus, campak 8.429 kasus, tetanus neonatrum (TN) sebanyak 10 penemuan kasus, dan penemuan kasus Non Polio Acute Flaccid Paralysis/lumpuh layu akut (AFP) sebanyak 1.527 kasus padahal capaian imunisasi dasar nasional mencapai $90,61 \% .^{3}$

Pada sebaran Jawa Timur masih ditemukan beberapa kasus PD3I seperti kasus TBC sebanyak 73.835 kasus, difteri 385 kasus, campak 401 kasus, non polio AFP 226 kasus. Penemuan ini bertolak belakang dengan capaian cakupan imunisasi yakni imunisasi campak/MR 97,8\%, imunisasi BCG 97,79\%, 
imunisasi DPT-HB-HiB (1) 99,47\%, imunisasi DPT-HB-HiB (3) 98,23\%. ${ }^{3}$

Kasus PD3I di Kabupten Jember juga msih banyak ditemukan, bahkan Kabupaten Jember ditetapkan sebagai daerah endemik TBC Jawa Timur dengan jumlah penderita baru TB $\mathrm{BTA}^{+}$pada tahun 2018 sebanyak 3.667 kasus. $^{4}$ Insidensi PD3I lain yang ditemukan dengan angka absolut di Jember secara berurutan adalah campak 435 kejadian, difteri 4 kejadian, pertusis 11 kejadian, dan TN 2 kejadian. Hal ini berbeda dengan hasil capaian cakupan diatas prosentase $80 \%$ dengan rincian cakupan imunisasi dasar lengkap $87,03 \%$, BCG $90,32 \%$, polio $86,93 \%$, campak $83,99 \%$, dan DPT-HB3 87,50\%. 5

Salah satu faktor masih ditemukannya kejadian PD3I adalah pengelolaan vaksin yang belum optimal. ${ }^{6}$ Di Kabupaten Jember terjadi ketidaksesuaian alokasi yang diterima Kabupaten Jember dari Provinsi. Kebutuhan logistik secara umum adalah 43.854 vaksin DPT-HB-HiB, 12.026 vaksin DT, dan 54.327 vaksin TD. Kebutuhan vaksin tersebut tidak terealisasi karena alokasi yang diterima Kabupaten Jember hanya sebanyak 41.134 vaksin DPT-HB-HiB dan 9.319 vaksin DT. Sedangkan untuk vaksin Td, Kabupaten Jember menerima vaksin melebihi kebutuhan yang direncanakan dengan alokasi yang diterima adalah 57.327. Bahkan penah terdapat vaksin campak sebanyak 490 vial dan pelarut campak sebanyak 490 pelarut dalam kondisi kadaluarsa. $^{7}$

Perbedaan alokasi akan mempengaruhi program imunisasi karena stock vaksin merupakan bahan utama pada penyelenggaraan imunisasi. Stock vaksin berkaitan dengan jumlah sasaran yang akan diimunisasi. $^{8}$

Telah banyak penelitian tentang program imunisasi maupun PD3I namun penelitian rantai dingin vaksin masih terbatas di Indonesia. Padahal penelitian manajemen rantai dingin vaksin dapat digunakan sebagai bahan evaluasi di pelayanan kesehatan khususnya puskesmas untuk melihat penjagaan vaksin agar daya guna vaksin dapat digunakan secara optimal. ${ }^{9,10}$

\section{METODE PENELITIAN}

Jenis penelitian yang digunakan adalah deskriptif dengan pendekatan kuantitatif observsional untuk mengamati suatu kondisi secara ilmiah. Subjek pada penelitian ini adalah petugas puskesmas yang bertanggung jawab terhadap pelaksanaan penjagaan vaksin.

Data yang diambil pada penelitian ini adalah data primer melalui wawancara petugas dan observasi, serta data sekunder dari Instalasi Farmasi Kesehatan (IFK) Kabupaten Jember sebagai penyedia vaksin tingkat kabupaten.

Penelitian ini dilaksanakan pada 31 Puskesmas yang tersebar di Kabupaten Jember dengan unit analisis bagian imunisasi setiap puskesmas. Adapun puskesmas pada penelitian ini adalah Puskesmas Nogosari, Balung, Lojejer, Kasiyan, Jenggawah, Ambulu, Sumberjambe, Pakusari, Silo I, Mangli, Bangsalsari, Sukorambi, Silo II, Kalisat, Panti, Banjarsengon, Rambipuji, Jelbuk, Kaliwates, Sumbersari, Mumbulsari, Patrang, Klatakan, Tanggul, Jember Kidul, Gladak Pakem, Arjasa, Sukowono, Ajung, dan Ledokombo. Penelitian juga melibatkan 31 petugas yang bertanggung jawab terhadap pelaksanaan kegiatan imunisasi termasuk rantai dingin. Para petugas menjadi narasumber penelitian untuk memperoleh informasi pelaksanaan rantai dingin vaksin di puskesmas yang bersangkutan.

\section{HASIL DAN PEMBAHASAN}

Hasil penelitian menunjukkan gambaran pelaksanaan manajemen rantai dingin vaksin pada 31 puskesmas di Kabupaten Jember berdasarkan 4 aspek yakni pengetahuan petugas, prasarana yang tersedia di puskesmas, kesesuaian pelaksanaan penyimpanan vaksin sesuai SOP, dan ketepatan suhu pada refrigerator. 


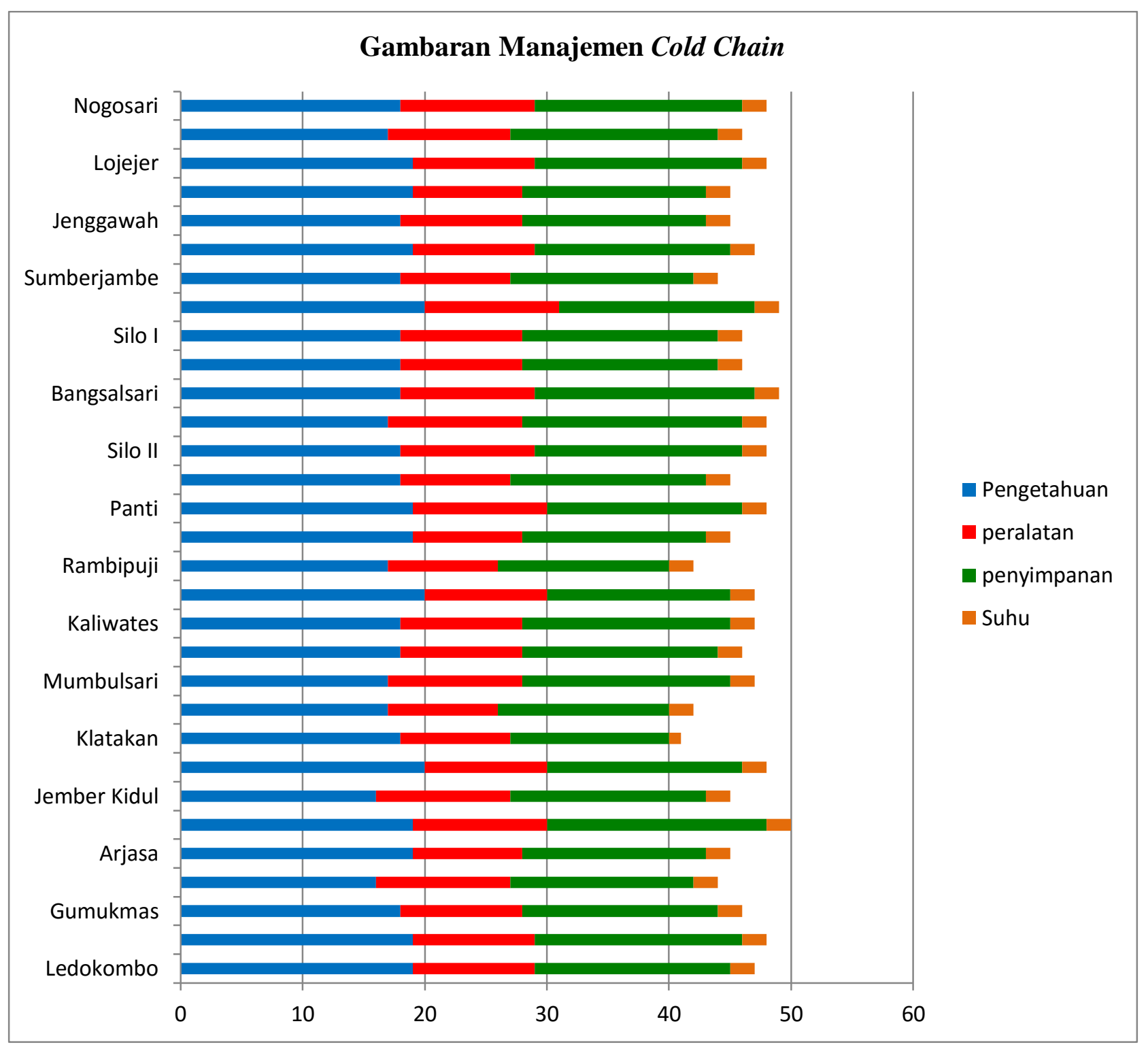

Gambar 1. Diagram Pelaksanaan Manajemen Rantai Dingin

Berdasarkan gambar 1 diketahui secara umum bahwa puskesmas dengan pelaksanaan manajemen rantai dingin yang baik adalah Puskesmas Jember Kidul. Sedangkan Puskesmas Klatakan perlu dilaksanakan perbaikan khususnya ketersediaan sarana sebagai penunjang keberhasilan kegiatan rantai dingin. Performa manajemen rantai dingin vaksin pada 31 Puskesmas diakumulasikan berdasarkan 4 aspek yakni pengetahuan, ketersediaan prasarana pendukung kegiatan manajemen rantai dingin, kesesuaian temperatur (monitoring temperatur), dan kesesuaian kegiatan penyimpanan terhadap SOP. Rincian setiap ditunjukkan pada setiap tabel selanjutnya. Pada tabel 1 ditunjukkan hasil penelitian berupa jenis pengetahuan, ketersediaan peralatan, dan kesesuaian temperatur.

Tabel 1. Aspek Manajemen Rantai Dingin Vaksin Berupa Pengetahuan, Ketersediaan peralatan, dan Kesesuaian Temperatur

\begin{tabular}{lcc}
\hline \multirow{2}{*}{ Jenis Pengetahuan } & \multicolumn{2}{c}{$\begin{array}{c}\text { Hasil } \\
\text { Hitung }\end{array}$} \\
\cline { 2 - 3 } & $\mathbf{N}$ & $\mathbf{\%}$ \\
\hline $\begin{array}{l}\text { Pengetahuan tentang Vaksin } \\
\text { Baik }\end{array}$ & 16 & 51,6 \\
$\quad$ Kurang baik & 15 & 48,4 \\
\hline $\begin{array}{l}\text { Pengetahuan tentang } \\
\text { dingin }\end{array}$ & Pengelolaan & rantai \\
$\quad$ Baik & 11 & 35,5 \\
$\quad$ Kurang baik & 20 & 64,5 \\
\hline
\end{tabular}




\begin{tabular}{|c|c|c|}
\hline \multicolumn{3}{|c|}{$\begin{array}{l}\text { Pengetahuan tentang pemeliharaan rantai } \\
\text { dingin }\end{array}$} \\
\hline Baik & 21 & 67,7 \\
\hline Kurang baik & 10 & 32,3 \\
\hline \multicolumn{3}{|c|}{ Ketersediaan Peralatan } \\
\hline Lengkap & 10 & 32,3 \\
\hline Tidak Lengkap & 21 & 67,7 \\
\hline \multicolumn{3}{|c|}{ Kesesuasian Temperatur } \\
\hline$<2^{\circ} \mathrm{C}$ & 1 & 3,2 \\
\hline $2^{\circ} \mathrm{C}-8^{\circ} \mathrm{C}$ & 30 & 96,8 \\
\hline$>8^{\circ} \mathrm{C}$ & 0 & 0 \\
\hline
\end{tabular}

Tabel 1 menunjukkan aspek pengetahuan tentang vaksin diketahui tingkat pengetahuan petugas cukup berimbang, sedangkan tingkat pengetahuan tentang pengelolaan rantai dingin paling banyak berada pada kategori kurang baik. Adapun pengetahuan tentang pemeliharaan tentang rantai dingin sebagian besar dalam kategori baik.

Pengetahuan merupakan unsur penting bagi individu atau petugas untuk menjalankan suatu kegiatan agar sesuai dengan pedoman. Bagi seorang petugas vaksin, pengetahuan tentang manajemen rantai dingin vaksin adalah unsur penting agar mampu menjaga vaksin sesuai dengan anjuran karena setiap vaksin memiliki perbedaan karakteristik berupa sensitifitas terhadap suhu sehingga setiap vaksin memiliki perbedaan perlakuan. Hal ini diungkapkan pada penelitian Kristini \& Dewi pengetahuan yang baik disertai praktik pengelolaan vaksin yang baik pula akan mampu menurunkan jumlah vaksin yang rusak. ${ }^{11}$

Sarana prasaran untuk rantai dingin yang diharuskan ada di setiap puskesmas adalah refrigerator khusus vaksin, cold pack, freeze tag, logtag VVCM, termometer, grafik catatan suhu, petunjuk pembacaan VVM, vaccine carrier, buku catatan stok vaksin, ADS, dan peralatan anafilaktik. sebagian besar sarana pendukung manajemen rantai dingin di puskesmas belum lengkap sebesar 21 puskesmas atau $67,7 \%$.

Peralatan yang memadai sesuai dengan SOP akan membantu terlaksananya kegiatan manajemen rantai dingin dengan optimal. Namun beberapa puskesmas di Kabupaten Jember memiliki kendala karena kondisi refrigerator yang dianjurkan sudah tidak dapat digunakan seperti yang dialami oleh Puskesmas Kasiyan, Rambipuji, dan Kalisat yang terpaksa memanfaatkan refrigerator jenis rumath tangga atau refrigerator buka pintu depan. Penggunaan refrigerator rumah tangga sudah tidak dianjurkan lagi karena memiliki kelemahan mudah tidak stabil menjaga temperatur dalam refrigerator pada kisaran temperatur $+2^{\circ} \mathrm{C}$ s $/ \mathrm{d}+8^{\circ} \mathrm{C} .{ }^{12,13}$ Sedangkan hal lain terjadi pada Puskesmas Klatakan yang terpaksa menggunanakn refrigerator pintu buka atas dalam kondisi yang tidak layak pakai karena sering memunculkan bunga es. Hal ini pun akan meningkatkan peluang vaksin rusak. Refrigerator yang digunakan oleh Puskesmas Klatakan telah bertentangan dengan anjuran WHO. Penggunaan refrigerator harus sesuai dengan anjuran WHO agar pada pelaksanaan penyimpanan vaksin harus menggunakan refrigerator layak dengan kondisi yang stabil mempertahankan temperatur. ${ }^{14}$

Vaksin adalah bahan biologis yang sensitif terhapad temperatur oleh karena itu penjagaan vaksin perlu perlakuan khusus dengan cara menyimpan vaksin pada refrigerator khusus dengan kondisi temperatur pada suhu $+2^{\circ} \mathrm{C} \mathrm{s} / \mathrm{d}+8^{\circ} \mathrm{C}$ serta selalu dilakukan monitoring temperatur setiap harinya. ${ }^{15,16}$ Namun berdasarkan tabel ditunjukkan masih terdapat satu puskes dengan kondisi temperatur refrigerator dibawah $+2^{\circ} \mathrm{C}$ yakni Puskesmas Klatakan. Adapun 30 puskesmas kondisi temperature selalu di kisaran $+2^{\circ} \mathrm{C}$ s/d $+8^{\circ} \mathrm{C}$ Kondisi suhu dibawah standart disebabkan refrigerator di Puskesmas Klatakan sering muncul bunga es dengan ketebalan lebih dari $5 \mathrm{~cm}$. Oleh karena itu, suhu didalam kulkas mudah turun bahkan penuturan petugas pernah hingga suhu minus. Kondisi yang dialami Puskesmas Klatakan dapat menghambat kegiatan imunisasi karena bahan utama kegiatan vaksin tidak dapat disimpan dalam waktu yang lama akibat kondisi refrigerator rusak. ${ }^{17}$ 
Tabel 2. Kesesuaian dengan SOP Penyimpanan

\begin{tabular}{|c|c|c|c|c|c|c|c|}
\hline \multirow{3}{*}{ No } & \multirow{3}{*}{ SOP } & \multicolumn{6}{|c|}{ Kesesuaian dengan SOP } \\
\hline & & \multicolumn{2}{|c|}{ Sesuai } & \multicolumn{2}{|c|}{ Tidak } & \multicolumn{2}{|c|}{ Total } \\
\hline & & $\mathbf{N}$ & $\%$ & $\mathbf{N}$ & $\%$ & $\mathbf{N}$ & $\%$ \\
\hline 1. & Refrigerator di posisi datar & 31 & 100 & 0 & 0 & 31 & 100 \\
\hline 2. & $\begin{array}{l}\text { Refrigerator terlindung dari sinar } \\
\text { matahari }\end{array}$ & 31 & 100 & 0 & 0 & 31 & 100 \\
\hline 3. & $\begin{array}{l}\text { Terdapat satu stabilisator setiap } \\
\text { lemari es }\end{array}$ & 25 & 80,6 & 6 & 19,4 & 31 & 100 \\
\hline 4. & $\begin{array}{l}\text { Satu stop kontak untuk satu } \\
\text { refrigerator }\end{array}$ & 23 & 74,2 & 8 & 25,8 & 31 & 100 \\
\hline 5. & $\begin{array}{l}\text { Jarak antara lemari es dengan } \\
\text { dinding adalah } 15-20 \mathrm{~cm}\end{array}$ & 27 & 87,1 & 4 & 12,9 & 31 & 100 \\
\hline 6. & $\begin{array}{l}\text { Tidak terdapat bunga es pada } \\
\text { evaporator }\end{array}$ & 15 & 48,4 & 16 & 51,6 & 31 & 100 \\
\hline 7. & $\begin{array}{l}\text { Grafik suhu diletakkan diatas } \\
\text { kulkas }\end{array}$ & 14 & 45,2 & 17 & 54,8 & 31 & 100 \\
\hline 8. & $\begin{array}{l}\text { Coolpack diletakkan pada bagian } \\
\text { dasar kulkas }\end{array}$ & 29 & 93,5 & 2 & 6,5 & 31 & 100 \\
\hline 9. & $\begin{array}{l}\text { Semua vaksin berada didalam } \\
\text { dus vaksin }\end{array}$ & 31 & 100 & 0 & 0 & 31 & 100 \\
\hline 10 & $\begin{array}{l}\text { Vaksin sensitif panas (BCG, } \\
\text { Campak, dan Polio) diletakkan } \\
\text { dekat evaporator }\end{array}$ & 30 & 96,8 & 1 & 3,2 & 31 & 100 \\
\hline 11. & $\begin{array}{l}\text { Vaksin sensitif beku (Hepatitis } \\
\text { B, DPT-HB, TT, DT dan Td) } \\
\text { diletakkan jauh evaporator }\end{array}$ & 30 & 96,8 & 1 & 3,2 & 31 & 100 \\
\hline 12. & $\begin{array}{l}\text { Pelarut disimpan pada suhu } \\
\text { ruang terlindung dari sinar } \\
\text { matahari langsung }\end{array}$ & 31 & 100 & 0 & 0 & 31 & 100 \\
\hline 13. & $\begin{array}{l}\text { Vaksin dengan masa kadaluarsa } \\
\text { pendek atau VVM B diletakkan } \\
\text { dibagian atas }\end{array}$ & 31 & 100 & 0 & 0 & 31 & 100 \\
\hline 14. & $\begin{array}{l}\text { Jarak antar dus vaksin } 1-2 \mathrm{~cm} \\
\text { untuk sirkulasi udara }\end{array}$ & 30 & 96,8 & 1 & 3,2 & 31 & 100 \\
\hline 15. & $\begin{array}{l}\text { Terdapat } 1 \text { buah termometer } \\
\text { yang diletakkan pada bagian } \\
\text { tengah diantara vaksin }\end{array}$ & 29 & 93,5 & 2 & 6,5 & 31 & 100 \\
\hline 16. & $\begin{array}{l}\text { Terdapat } 1 \text { buah alat pemantau } \\
\text { paparan beku diantara vaksin } \\
\text { yang sensitif beku }\end{array}$ & 27 & 87,1 & 4 & 12,9 & 31 & 100 \\
\hline 17. & $\begin{array}{l}\text { Terdapat VVCM yang } \\
\text { diletakkan pada tempat } \\
\text { penyimpanan vaksin BCG }\end{array}$ & 30 & 96,8 & 1 & 3,2 & 31 & 100 \\
\hline
\end{tabular}

Pedoman penyimpanan vaksin atau Standart Operasional Prosedur (SOP) telah disusun oleh Kementerian Kesehatan Republik Indonesia sejak 2012 dan harus dilaksanakan sesuai anjuran oleh setiap sektor logistik mulai tingkat provinsi, kabupaten/kota, hingga puskesmas. Secara umum setiap vaksin harus disimpan pada suhu $+2^{\circ} \mathrm{C}$ s $/ \mathrm{d}+8^{\circ} \mathrm{C} .{ }^{18}$ Hasil penelitian pada aspek kesesuaian pelaksanaan penyimpanan vaksin dengan SOP ditunjukkan pada tabel 2. Pada tabel tersebut menunjukkan terdapat beberapa SOP yang tidak dilaksanakan oleh Puskesmas. 
Pedoman penyimpanan vaksin atau Standart Operasional Prosedur (SOP) telah disusun oleh Kementerian Kesehatan Republik Indonesia sejak 2012 dan harus dilaksanakan sesuai anjuran oleh setiap sektor logistik mulai tingkat provinsi, kabupaten/kota, hingga puskesmas. Secara umum setiap vaksin harus disimpan pada suhu $+2^{\circ} \mathrm{C} \mathrm{s} / \mathrm{d}+8^{\circ} \mathrm{C} .{ }^{18}$ Hasil penelitian pada aspek kesesuaian pelaksanaan penyimpanan vaksin dengan SOP ditunjukkan pada tabel 2. Pada tabel tersebut menunjukkan terdapat beberapa SOP yang tidak dilaksanakan oleh puskesmas.

Penemuan pada penelitian paling banyak yang tidak sesuai dengan SOP adalah masih ditemukannya bunga es di dalam refrigerator. Kemunculan bunga es di Puskesmas Ledokombo, Ajung, Gumukmas, Jember Kidul, Tanggul, Patrang, Mumbulsari, Sumbersari, Jelbuk, Rambipuji, Banjarsengon, Panti, Silo II, Mangli, Silo I, Pakusari, Sumberjambe, Ambulu, Jenggawah, Kasiyan, dan Nogosari tidak membahayakan kondisi vaksin dan masih pada ambang ketebalan yang diperbolehkan yakni dibawah $5 \mathrm{~cm}$. Kemunculan bunga es yang membahayakan vaksin terjadi pada refrigerator Puskesmas Klatakan karena ketebalan bunga es melebihi ambang batas. SOP lain yang masih banyak tidak dipatuhi adalah grafik suhu tidak diletakan diatas kulkas, satu stop kontak khusus untuk satu kulkas, stabilisator setiap kulkas, ukuran jarak lemari es dengan dinding, peletakan coolpack di dasar kulkas, peletakan satu thermometer pada bagian tengah diantara vaksin, dan peletakan alat pantau suhu beku. Hasil observasi disetiap puskesmas didapatkan hasil bahwa hanya Puskesmas Klatakan meletakan vaksin tidak sesuai karakteristik sensitifitas vaksin. Kondisi tersebut didukung akibat refrigerator tidak layak pakai dan tidak ada pengganti refrigerator yang layak.

\section{KESIMPULAN}

Kesimpulan dari penelitian ini adalah tingkat pengetahuan tentang pengelolaan rantai dingin vaksin beberapa petugas masih kurang baik sehingga perlu akselerasi peningkatan pengetahuan. Aspek sarana prasarana masih terdapat beberapa puskesmas yang mengalami hambatan akibat peralatan yang kurang memadai sehingga SOP penyimpanan tidak dapat dilaksanakan secara optimal. Kesesuaian temperatur refrigerator sudah cukup baik hanya satu puskesmas yang perlu perbaikan segera dengan pengadaan refrigerator layak pakai. Kepatuhan terhadap SOP Penyimpanan vaksin masih belum terlaksana secara maksimal. Kepatuhan terhadap SOP belum maksimal dengan penemuan ketidakpatuahan sebagai berikut masih terdapat bunga es di beberapa refrigerator puskesmas, peletakan grafik tidak sesuai anjuran, tidak menyediakan satu stop kontak untuk satu refrigerator, dan peletakan jarak setiap vaksin kurang dari 15-20 cm.

\section{UCAPAN TERIMA KASIH}

Terima kasih diucapkan kepada semua pihak yang telah membantu dalam penelitian ini khususnya kepada Dinas Kesehatan kabupaten Jember, Instalasi Faramsi Kabupaten, dan Puskesmas yang telah bersedia membantu proses penelitian.

\section{DAFTAR PUSTAKA}

1. Program for Appropriate Technology in Health. 2011. An Assessment of Vaccine Supply Chain and Logistics Systems in Thailand. PATH.

2. Oxford Vaccine Group. (2016, April 26). Oxford Vaccine Group. Dipetik November 6, 2019, dari University of Oxford:

https://www.ovg.ox.ac.uk/news/herdimmunity-how-does-it-work

3. Kementerian Kesehatan Republik Indonesia. 2019. Profil Kesehatan Indonesia Tahun 2018. Jakarta: Kementerian Kesehatan Republik Indonesia.

4. Dinas Kesehatan Kabupaten Jember. 2018. Profil Kesehatan Kabupaten Jember Tahun 2017. Jember: Dinas Kesehatan Kabupaten Jember.

5. Dinas Kesehatan Provinsi Jawa Timur. 2018. Profil Kesehatan Provinsi Jawa Timur Tahun 2017 . Surabaya: Dinas Kesehatan Provinsi Jawa Timur.

6. De, B. S. 2013. Pengaruh Reaksi Imunisasi Campak Terhadap Sikap dan Perilaku Ibu dalam Pelaksanaan Imunisasi Campak di Kota Semarang. Semarang: 
Media Medika Muda. FK. Universitas Dipenogoro

7. Instalasi Farmasi Kesehatan Kabupaten Jember. 2020. Persediaan Obat dan Perbekalan Kesehatan di Instalasi Farmasi Kabupaten Jember Tahun 2019. Instalasi Farmasi Kesehatan Kabupaten Jember: Instalasi Farmasi Kesehatan Kabupaten Jember.

8. Gooding, E., Spiliotopoulou, E., \& Yadav, P. 2019. Impact of vaccine Stockout on Immunization Coverage in Nigeria. Journal of Vaccine Tilburg University, 37(35):5104-5110.

9. Philips, D. E., Dieleman, J. L., Lim, S. S., \& Shearer, J. 2017. Determinant of Effective Vaccine Coverage in Low and Middle-Income Countries: a Systematic Review and Interpretative Synthesis. BioMed Central, 17 (2017):681.

10. Weltermann, B. M., Markic, M., Thielmann, A., Gesenhues, S., \& Hermann, M. 2014. Vaccination Management and Vaccination Errors: A Representative Online-Survey among Primary Care Physician. Journal of Plos One, 9(8):105119.

11. Kristini, \& Dewi, T. (2008). Faktor-faktor Risiko Kualitas Pengelolaan Vaksin Program Imunisasi yang Buruk di Unit Pelayanan Swasta (Studi Kasus di Kota Semarang). Tesis. Semarang: Universitas Diponogoro.

12. Ranuh, I. G., Suyitno, H., Hadinegoro, S. R., Kartasasmita, C. B., Ismoedijanto, \& Soejatmiko. (2011). Pedoman Imunisasi di Indonesia Edisi Keempat. Ikatan Dokter Anak Indonesia Ranuh, I. G., Suyitno, H., Hadineoro, S. S., Kartasasmitra, G. B., Ismoedijanto, \& Soedjatmiko. 2014. Pedoman Imunisasi di Indonesia (Edisi 4). Jakarta: Ikatan Dokter Anak Indonesia.

13. Kementerian Kesehatan Republik Indonesia. 2013. Peraturan Menteri Kesehatan Republik Indonesia Nomor 42 Tahun 2013 Tentang Penyelenggaraan Imunisasi. Jakarta: Kementerian Kesehatan Republik Indonesia.

14. World Health Organization. 2015. Immunization in Practice, A Practical Guide for Health Staff. Geneva: WHO Press.
15. Unicef. 2014. Cold Chain Support Package Procurement Guidelines Temperature Monitoring Device. New York City: Unicef.

16. Govani, K. J., \& Sheth , J. K. 2015. Evaluation of Temperature Monitoring System of Cold Chain at all Urban Health Centres (UHCs) of Ahmedabad Municipal Corporation (AMC) area. Healthline Journal, 6(1):41-45.

17. Ashok, A., Brison, M., \& LeTallec, Y. 2017. Improving Cold Chain Systems: Challenges and Solutions. Elsevier, 35(2017):2217-2223.

18. Kementerian Kesehatan Republik Indonesia. 2017. Peraturan Menteri Kesehatan Republik Indonesia Nomor 12 Tahun 2017 tentang Penyelenggaraan Imunisasi. Jakarta: Kementerian Kesehatan Republik Indonesia. 